\title{
Effect of Cold Rolling on the Mechanical Properties and Formability of FSWed Sheets in AA5754-H114
}

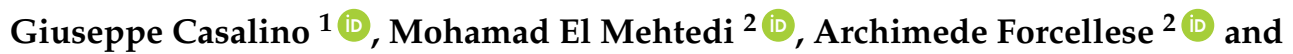 \\ Michela Simoncini ${ }^{3, * \text { (D) }}$ \\ 1 Dipartimento di Meccanica Management Matematica (DMMM), Politecnico di Bari, Viale Japigia 182, \\ 70126 Bari, Italy; giuseppe.casalino@poliba.it \\ 2 Dipartimento di Ingegneria Industriale e Scienze Matematiche (DIISM), Università Politecnica delle Marche, \\ Via Brecce Bianche, 60100 Ancona, Italy; elmehtedi@univpm.it (M.E.M.); a.forcellese@univpm.it (A.F.) \\ 3 Università degli Studi eCampus, Via Isimabrdi 10, 22060 Novedrate, Italy \\ * Correspondence: michela.simoncini@uniecampus.it; Tel.: +39-071-220-4798
}

Received: 27 February 2018; Accepted: 25 March 2018; Published: 28 March 2018

\begin{abstract}
The effect of cold rolling, performed after friction stir welding (FSW), on the mechanical properties and formability of joints in AA5754-H114 aluminium alloy was investigated. Friction stir welding was carried out on $2.5 \mathrm{~mm}$ thick sheets with constant values of rotational and welding speeds of $1200 \mathrm{rpm}$ and $100 \mathrm{~mm} / \mathrm{min}$, respectively. Then, FSWed workpieces were cold rolled, with the rolling direction perpendicular to the welding line, in order to obtain height reductions ranging from 0.1 to $0.5 \mathrm{~mm}$. Cold rolling with the same height reductions was also carried out on the base material in the as-received condition. The mechanical properties and formability of both friction stir welded joints and base material, before and after cold rolling, were evaluated by means of the uniaxial tensile and hemispherical punch tests. The nominal stress vs. nominal strain and punch force vs. punch stroke curves were analysed in detail. Finally, the scanning electron microscope fractography was used to evaluate the fractured surface of tensile samples.
\end{abstract}

Keywords: friction stir welding; cold rolling; mechanical properties; formability; scanning electron microscopy analysis

\section{Introduction}

Friction Stir Welding (FSW) is a solid state process developed for the obtaining of joints with higher mechanical properties and formability than those provided by fusion welding technologies [1-8]. Manufacturing of multi-sheet structures obtained by assembling two or more blanks, also using different materials and/or thicknesses, is the industrial field able to obtain the greatest benefits by FSW. Another area of interest is represented by the joining of un-weldable alloys through fusion technologies [1,9-13].

In the FSW a tool, with a shoulder and a profiled pin, is used to weld sheet workpieces without reaching the melting temperature of workpiece material. Frictional heat, generated between the rotating tool and blanks, leads to the formation of a softened and dynamically recrystallised zone, i.e., nugget, which approximately corresponds to the location of the pin tool during welding. As the rotating tool is moved along the welding line, it mechanically intermixes the workpieces from the advancing to the retreating side. Therefore, the FSW process exploits the frictional heat generated between tool and workpieces, along with that generated by the stirring action of the tool and the adiabatic heat within the material, to promote a strong plastic deformation of the workpieces and their complex mixing across the weld [1,14-19]. 
Notwithstanding the several advantages provided, FSW is characterised by some drawbacks which can reduce its application if joints with high strength are required. An important limitation is the forging action applied by the tool shoulder, necessary to generate frictional heating, which causes a thickness decrease in an area whose width and length are equal to the shoulder diameter and tool travel along the welding line, respectively [20]. Such thinning produces the reduction of both mechanical properties and formability of joints, with an effect that becomes ever more marked as the initial sheet thickness decreases. Forging also leads to the worsening of aesthetic appearance of the welded workpieces.

A further aspect referred to as a limitation in friction stir welding is related to the small geometric clearance between the bottom side of the pin and backing plate which is necessary to avoid their direct contact during the welding process [21,22]. Depending on the tool geometry and process parameters, it can cause the formation of a small discontinuity (kissing bond) located at the root of the weld, which reduces the effective cross-sectional area of weld. Furthermore, the discontinuity acts as a notch involving a local increase in the intensity of stress field and, consequently, a quicker crack propagation as joints are subjected to post-welding forming processes.

An approach developed by the authors to remove the forging effect by ensuring a constant sheet thickness was to subject the friction stir welded (FSWed) workpieces to cold rolling (CR) [23]. Rolling could be also useful to reduce the depth of the discontinuity at the bottom surface of weld. In order to obtain such results, the height reduction of cold rolling should be accurately chosen by additionally taking into account the strain hardening effect due to cold deformation on the mechanical properties and formability of the welded blank.

In this framework, the present work aims to investigate the influence of the cold rolling process on the mechanical properties and formability of friction stir welded sheets in AA5754-H114 aluminium alloy. FSW experiments were carried out on sheet workpieces with a thickness of $2.5 \mathrm{~mm}$. Then, the welds were cold rolled, with the rolling direction perpendicular to the welding line, by imparting one or more passes, each of them with a height reduction of $0.1 \mathrm{~mm}$. The effect of FSW on the final properties of sheet workpieces was studied by performing cold rolling on the base material in the as-received condition. The mechanical properties and formability of FSWed joints and base material, before and after cold rolling, were evaluated by means of uniaxial tensile and hemispherical punch tests. The tensile specimens were also subjected to micro-fractography analyses performed by means of scanning electron microscopy.

\section{Material and Experimental Procedures}

\subsection{Material}

The material used was AA5754 aluminium alloy, supplied in form of $2.5 \mathrm{~mm}$ thick sheets, in the H-114 temper state. The chemical composition of the alloy is shown in Table 1. This alloy is used in the aeronautic and automotive industries for structural panels, owing to its excellent corrosion resistance properties, especially to seawater and industrially polluted atmospheres.

Table 1. Chemical composition of AA AA5754 aluminium alloy (wt. \%).

\begin{tabular}{cccccccccc}
\hline $\mathbf{Z n}$ & $\mathbf{C u}$ & $\mathbf{M n}$ & $\mathbf{S i}$ & $\mathbf{F e}$ & $\mathbf{M g}$ & $\mathbf{C r}$ & $\mathrm{Ti}$ & $\mathrm{Ni}$ & $\mathrm{Al}$ \\
\hline 0.2 & 0.1 & 0.5 & 0.4 & 0.4 & $2.6-3.6$ & 0.3 & 0.15 & - & Bal. \\
\hline
\end{tabular}

\subsection{Friction Stir Welding}

Butt joints were obtained by FSW experiments carried out, using the computer numerical control machining center COMEC M50, on sheet workpieces with a length, width and thickness equal to $185 \mathrm{~mm}, 80 \mathrm{~mm}$ and $2.5 \mathrm{~mm}$, respectively (Figure 1). Table 2 specifies the geometric features of pin tool, and Table 3 shows the welding parameters defined in a previous study in which the weldability 
of AA5754-H114 alloy was investigated [24]. Experiments were carried out by keeping constant the values of rotational speed, welding speed and tool sinking during the welding stage; the welding line was perpendicular to the rolling direction of sheets in the as-received condition.

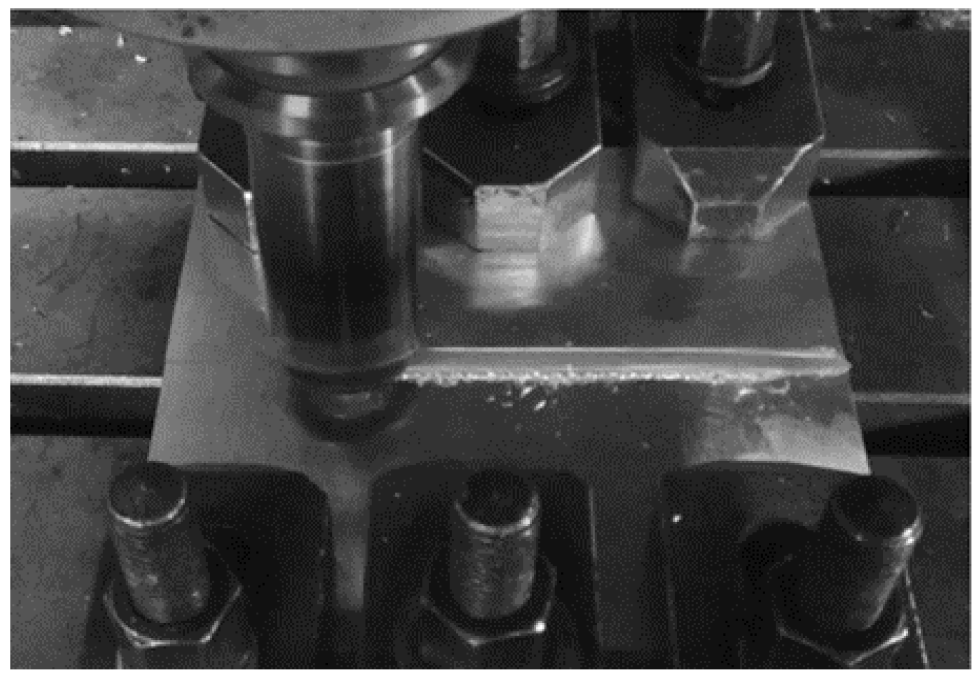

Figure 1. Experimental setup of the Friction Stir Welding (FSW) process.

Table 2. Geometric features of the conical pin tool in $\mathrm{H} 13$ tool steel used in the FSW experiments.

\begin{tabular}{cc}
\hline Feature & Value \\
\hline Shoulder diameter $[\mathrm{mm}]$ & 15 \\
Cone base diameter $[\mathrm{mm}]$ & 3.9 \\
Pin height $[\mathrm{mm}]$ & 2.3 \\
Pin angle $\left[{ }^{\circ}\right]$ & 30 \\
\hline
\end{tabular}

Table 3. Welding process parameters.

\begin{tabular}{cc}
\hline Parameter & Value \\
\hline Rotational speed $[\mathrm{rpm}]$ & 1200 \\
Welding speed $[\mathrm{mm} / \mathrm{min}]$ & 100 \\
Tool sinking $[\mathrm{mm}]$ & 0.08 \\
Plunging angle $\left[^{\circ}\right]$ & 2 \\
\hline
\end{tabular}

\subsection{Cold Rolling}

The FSWed workpieces were cold rolled after joining (FSWed+CRed condition). The CR process was performed on strips, $90 \mathrm{~mm}$ in width and $170 \mathrm{~mm}$ in length, obtained by water jet cutting the FSWed joints so that the length side of the strip was perpendicular to the welding line. The strips were obtained in the central zone of the weld in which the FSW process can be considered stationary. The height reduction $(\Delta h)$ of each rolling pass was equal to $0.1 \mathrm{~mm}$. Strips with an uniform thickness equal to $2.4,2.3,2.2,2.1$ and $2.0 \mathrm{~mm}$ were obtained with a number of passes rising from 1 to 5 , respectively.

Cold rolling was also carried out on strips, $90 \mathrm{~mm}$ in width, $170 \mathrm{~mm}$ in length and $2.5 \mathrm{~mm}$ in thickness, cut from the base material (BM) in order to obtain the same thicknesses of the FSWed+CRed strips. The length side of BM+CRed strips was parallel to the rolling direction of AA5754 sheet in the as-received condition. 


\subsection{Uniaxial Tensile Tests}

The effect of cold rolling on the mechanical properties of both FSWed and BM blanks was investigated by carrying out room temperature uniaxial tensile tests performed, according to ASTM E8/E8M and BS EN 895, on the servo-hydraulic universal testing machine MTS 810. The tests were carried out with a constant traverse speed equal to $0.1 \mathrm{~mm} / \mathrm{s}$. Both FSWed+CRed and BM+CRed strips, after cold rolling with $\Delta h$ values ranging between 0.1 and $0.5 \mathrm{~mm}$, were machined to obtain tensile samples with loading direction parallel to the cold rolling one. Tensile tests were also carried out on the FSWed workpieces and BM before cold rolling on samples with the loading direction perpendicular to welding line and parallel to the rolling direction of AA5754 sheets in the as-received condition, respectively. At least three repetitions for each condition were undertaken. Nominal stress $(S)$ and nominal strain $(e)$ were acquired during testing. The yield strength $(Y S)$, ultimate tensile strength $(U T S)$ and ultimate elongation in percentage (UE) were derived from the $S$-e curves. Finally, the true stresses and true strains in the region of uniform plastic deformation were calculated and processed to evaluate the work hardening behaviour in both FSWed+CRed and BM+CRed conditions.

\subsection{Formability Tests}

The influence of cold rolling on the room temperature formability of both welded workpieces and base material was studied using the hemispherical punch test carried out on the servo-hydraulic universal testing machine MTS 810. The punch speed was kept constant and equal to $0.1 \mathrm{~mm} / \mathrm{s}$. Both FSWed and BM strips, after cold rolling with $\Delta h$ values varying from 0.1 to $0.5 \mathrm{~mm}$, were machined to obtain $90 \mathrm{~mm} \times 90 \mathrm{~mm}$ square samples. Hemispherical punch tests were also carried out on the FSWed and BM samples before cold rolling.

The FSWed and FSWed+CRed samples were placed on the die with the side that was in touch with shoulder during welding opposed to the hemispherical punch surface.

The punch load $(F)$ and punch stroke $(\Delta s)$ were recorded during testing. Formability was measured by the limiting dome height $(L D H)$ defined by the punch stroke at the peak of the load vs. stroke curve. For each process condition, experimental trials were repeated at least three times.

\subsection{Microstructural Analysis}

The scanning electron microscope (SEM) Philips XL20 (Philips, Amsterdam, The Netherlands), in backscattered electron mode, was used to obtain high magnification images of fractured surfaces. To this end, the tensile tested fracture surfaces were cleaned by means of ultrasonic cleaner with acetone for $10 \mathrm{~min}$; then, they were analysed by SEM in order to accurately identify the fracture mechanisms as a function of the height reduction imposed by cold rolling process on both FSWed and BM workpieces.

\section{Experimental Results}

\subsection{Effect of Cold Rolling on the Mechanical Properties of FSWed Workpieces}

The nominal stress vs. nominal strain curves of AA5754-H114 aluminium alloy in the FSWed+CRed condition are shown in Figure 2a in which the $S-e$ plot of FSWed workpiece before cold rolling is also reported for reference. After reaching the peak value, the flow stress does not exhibit any appreciable decrease with increasing strain before failure, i.e., the tensile sample does not show a significant necking. Fracture takes place along the welding line and sheet thinning is localised in the fractured zone (Figure $2 b$ ). Such behaviour becomes ever more evident as the number of cold rolling passes increases. Furthermore, for a given strain, the $S$ value obtained by deforming FSWed+CRed samples is higher than that given by FSWed one; such discrepancy monotonically increases with $\Delta h$. Finally, the FSWed+CRed samples exhibit values of the ultimate elongation lower than that of the FSWed one; such difference grows with height reduction applied by cold rolling. 
The plastic flow behaviour of the base material is characterised by a post-necking deformation before failure (Figure 2c) much more pronounced than in the FSWed samples (Figure 2a). The sheet thinning distributed throughout the gauge length and the post-necking deformation decreases as the number of cold rolling passes increases (Figure 2d). Furthermore, according to the behaviour exhibited by tensile samples in the FSWed+CRed condition, the $S$ value obtained by deforming BM+CRed samples is significantly higher than that provided by BM with a discrepancy growing with height reduction. When considering ductility, the $U E_{B M+C R e d}$ values are lower than $U E_{B M}$ with a gap rising with $\Delta h$.

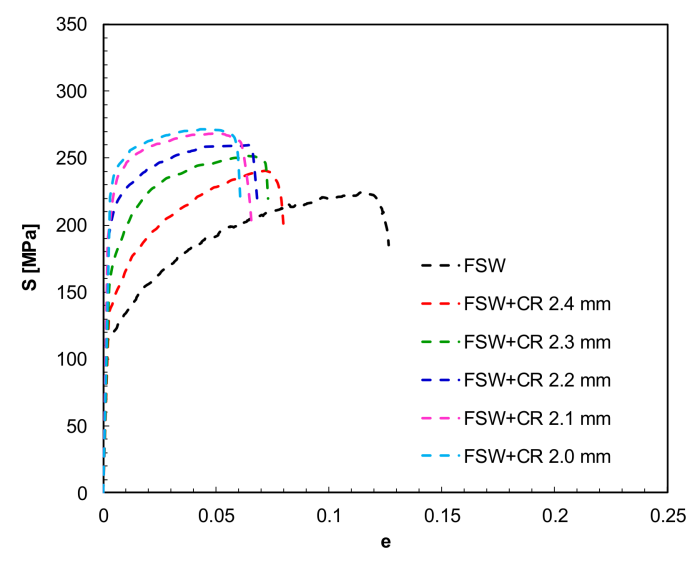

(a)

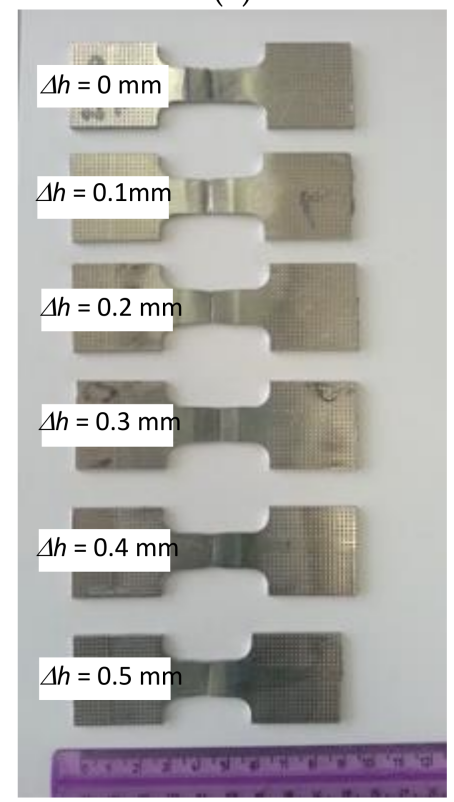

(b)

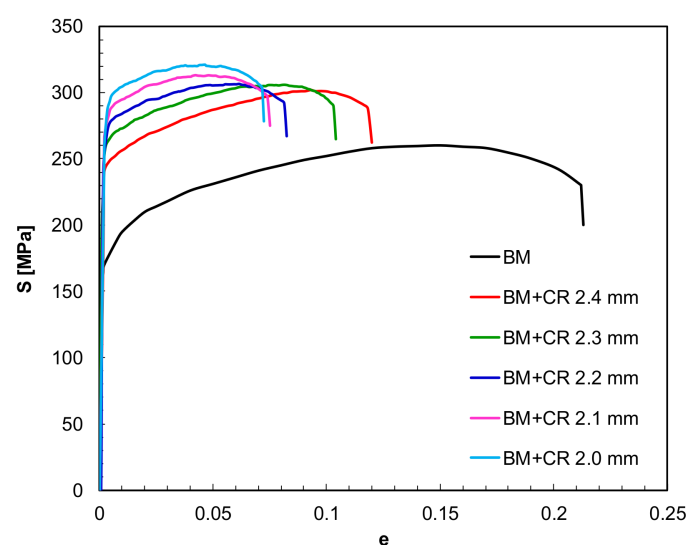

(c)

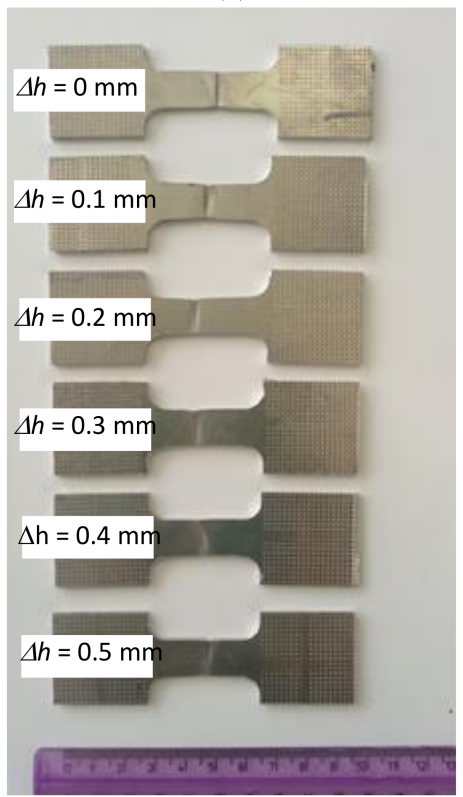

(d)

Figure 2. Typical nominal stress vs. nominal strain curves and fractured tension tested samples: (a) S-e curves and (b) fractured samples in the FSWed+CRed condition; (c) S-e curves; and (d) fractured samples in the $\mathrm{BM}+\mathrm{CRed}$ condition.

Figure 3 shows the comparison between mechanical behaviour exhibited by AA5754-H114 alloy in the FSWed+CRed and BM+CRed conditions. Irrespective of height reduction, the yield strength and ultimate tensile strength in the FSWed+CRed condition are lower than those of the BM+CRed (Figure 3a,b); such results are consistent with those exhibited by the FSWed and BM samples before cold rolling $(\Delta h=0)$. The growth rates of $Y S$ and UTS with $\Delta h$ are almost independent to the number 
of rolling passes. By considering the base material, both $Y S$ and UTS strongly increases after the first rolling pass $(\Delta h=0.1 \mathrm{~mm})$; then, their growth rates decrease and kept to an almost constant value. As ductility is considered (Figure 3c), irrespective of $\Delta h$ value, the ultimate elongation in the FSWed+CRed condition is lower than that of the BM+CRed. This is consistent with the behaviour exhibited by FSWed and BM samples before cold rolling. However, while the discrepancy between $U E_{B M}$ and $U E_{F S W}$ is equal to $42.9 \%$, the difference between the $U E_{B M+C R e d}$ and $U E_{F S W+C R e d}$ decreases from $35.8 \%$ with $\Delta h=0.1 \mathrm{~mm}$ to $19.1 \%$ with $\Delta h=0.5 \mathrm{~mm}$. It means that the cold rolling process leads to a much less pronounced decrease of ductility in the FSWed workpieces than in the BM.

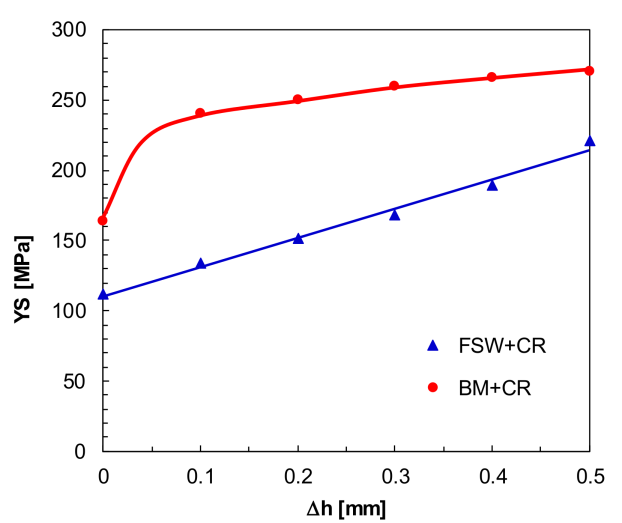

(a)

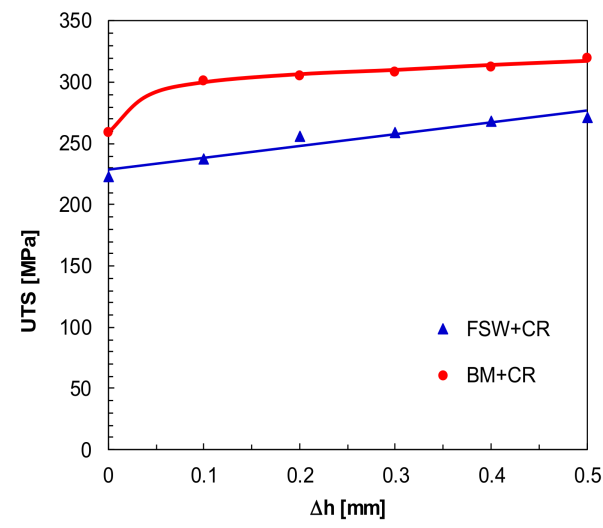

(b)

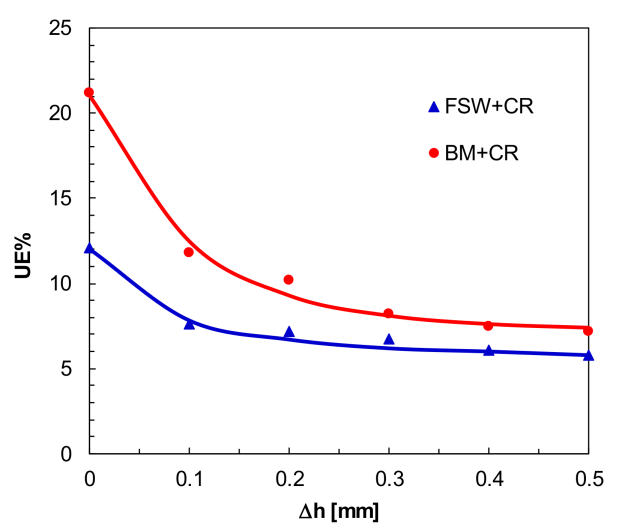

(c)

Figure 3. Comparison between the mechanical behaviour exhibited by the FSWed+CRed and BM+CRed samples in terms of: (a) Yield strength vs. height reduction; (b) Ultimate tensile strength vs. height reduction; (c) Ultimate elongation vs. height reduction.

Figure 4 shows the SEM images of the fractured surfaces exhibited by the FSWed and FSWed+CRed samples. Irrespective of the height reduction imposed by cold rolling, they reveal a ductile behaviour with microvoid coalescence (Figure $4 a, c, e)$. In fact, tensile loading results in equiaxed dimples that coalesce perpendicular to the loading direction. However, cracks propagating along the direction of welding motion can be also seen (Figure $4 \mathrm{~b}, \mathrm{~d}, \mathrm{f}$ ); furthermore, the extent of cracks tends to increase with the height reduction. The SEM images of the BM and BM+CRed samples show a ductile fracture surface morphology which is not influenced by height reduction (Figure 5) indicating that, in the experimental conditions of the present work, cold rolling does not significantly affect the fracture mechanisms. Finally, the cracks observed in the welded samples are not present in the BM both before and after cold rolling. 


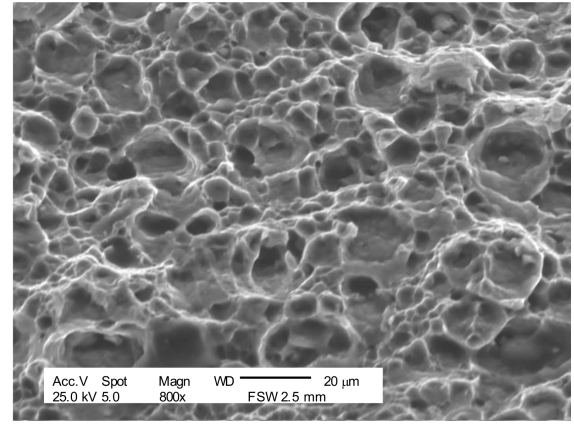

(a)

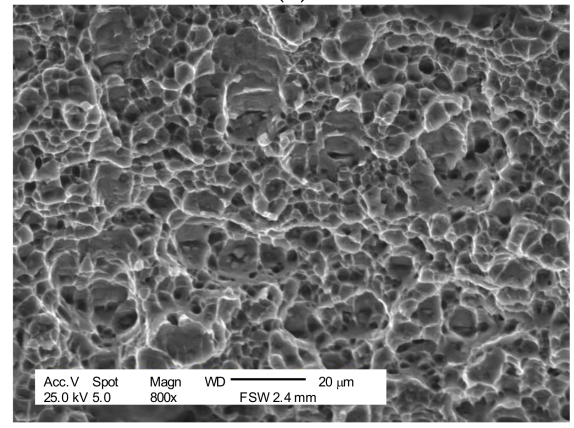

(c)

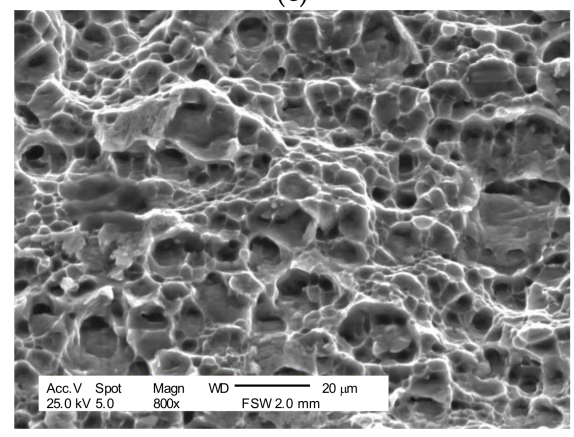

(e)

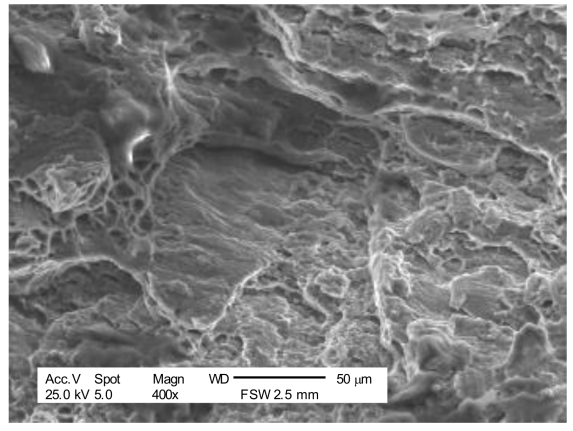

(b)

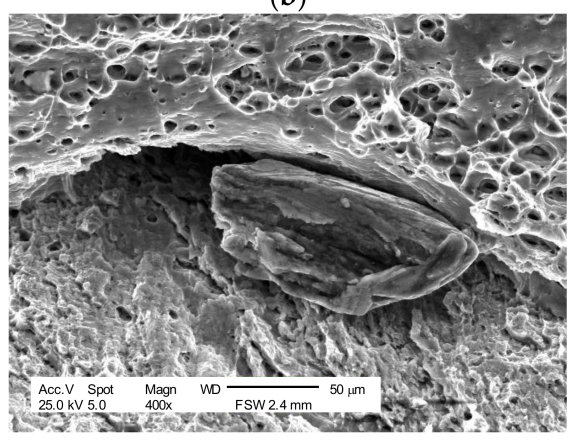

(d)

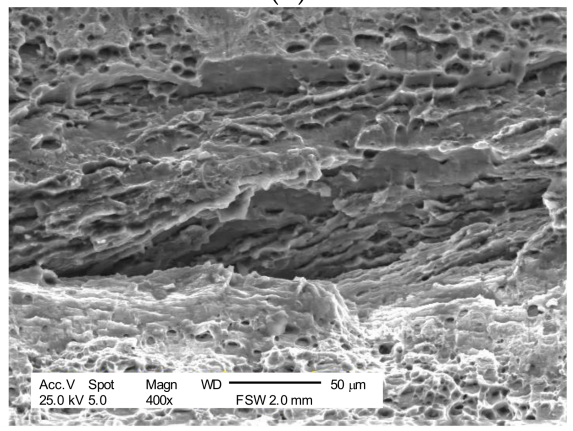

(f)

Figure 4. Scanning electron microscope fractography of the FSWed and FSWed+CRed samples deformed along the cold rolling direction: (a) $\Delta h=0 \mathrm{~mm}$ (lower magnification); (b) $\Delta h=0 \mathrm{~mm}$ (higher magnification); (c) $\Delta h=0.1 \mathrm{~mm}$ (lower magnification); (d) $\Delta h=0.1 \mathrm{~mm}$ (higher magnification); (e) $\Delta h=0.5 \mathrm{~mm}$ (lower magnification); (f) $\Delta h=0.5 \mathrm{~mm}$ (higher magnification).

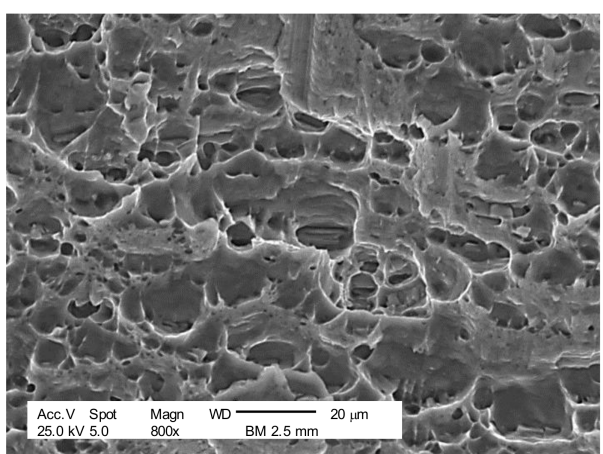

(a)

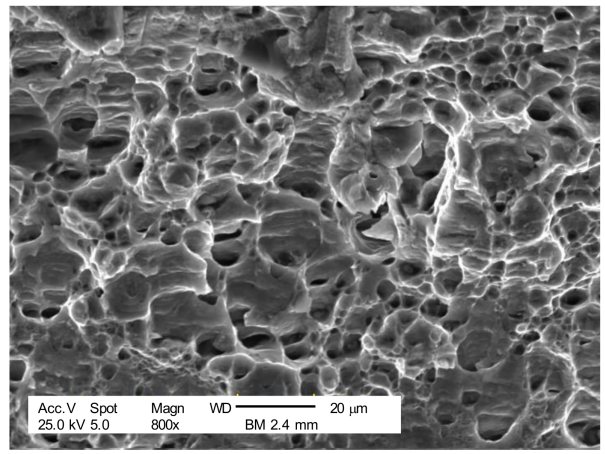

(b)

Figure 5. Cont. 


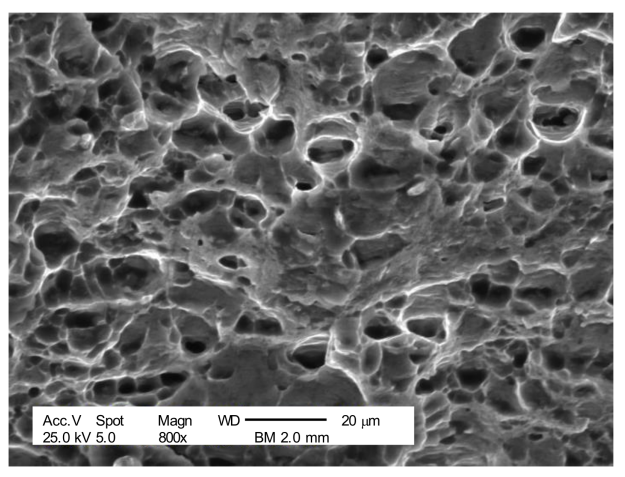

(c)

Figure 5. Scanning electron microscope fractography of the BM+CRed samples deformed along the cold rolling direction: (a) $\Delta h=0 \mathrm{~mm}$; (b) $\Delta h=0.1 \mathrm{~mm}$; (c) $\Delta h=0.5 \mathrm{~mm}$.

\subsection{Effect of Cold Rolling on the Formability of FSWed Workpieces}

The results of a hemispherical punch test on AA5754-H114 alloy in the FSWed+CRed condition, expressed in terms of punch load vs. stroke curve, are shown in Figure 6a in which they are compared with the $F-\Delta s$ curve of FSWed sample. A reduction in the peak value of the $F$ - $\Delta s$ curve, i.e., in the limiting dome height, with increasing the number of cold rolling passes clearly appears (Figure 7a). Such decrease takes place at a lower rate until $\Delta h<0.3 \mathrm{~mm}$ and at a higher rate as $\Delta h \geq 0.3 \mathrm{~mm}$. Furthermore, the peak value of the punch load decreases with $\Delta h$ due to the reduction of both the punch stroke until failure and sheet thickness. In addition, the BM+CRed samples exhibit a behaviour characterised by a decrease in the $L D H$ with increasing $\Delta h$ (Figures $6 \mathrm{~b}$ and $7 \mathrm{~b}$ ). However, the strong reduction in the limiting dome height observed for high $\Delta h$ values in the FSWed+CRed condition does not occur.

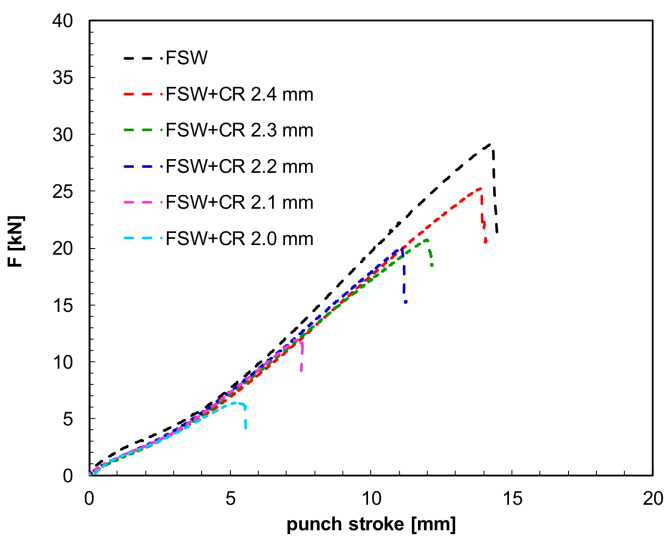

(a)

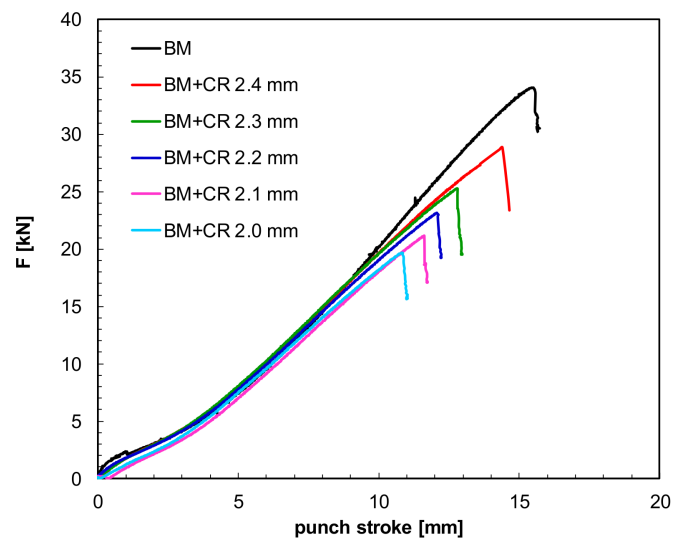

(b)

Figure 6. Punch load vs. stroke curves obtained by hemispherical punch test performed on: (a) FSWed+CRed and (b) BM+CRed samples.

Figure 8a shows the comparison between FSWed+CRed and BM+CRed samples in terms of punch stroke at the peak value of the load vs. stroke curve. Consistent with the behaviour exhibited by the FSWed and BM samples, before cold rolling, the $L D H$ values in the FSWed+CRed condition are slightly lower than those of $B M+C R e d$ until a height reduction equal to $0.2 \mathrm{~mm}$ is reached. Then, the discrepancy strongly increases and, as $\Delta h=0.5 \mathrm{~mm}$, the $L H D_{F S W e d+C R e d}$ is about half of $L H D_{B M+C R e d}$. 


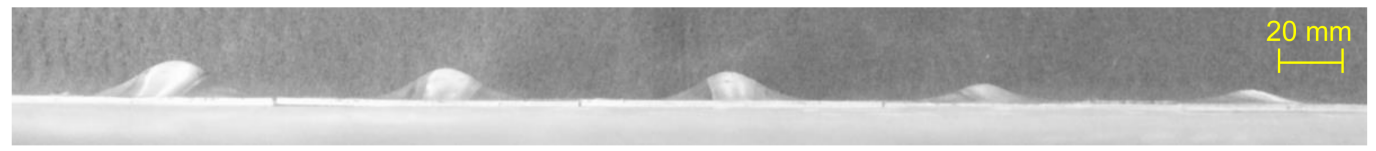

(a)

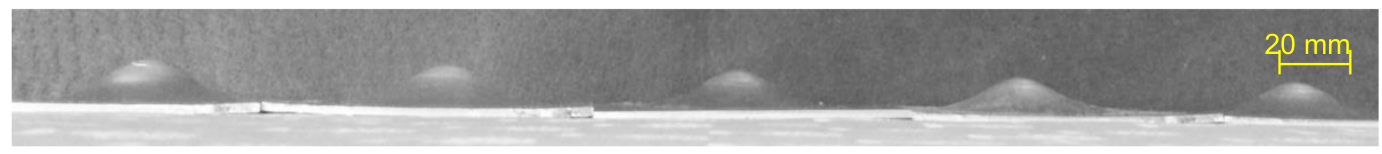

(b)

Figure 7. Samples deformed by means of hemispherical punch test: (a) FSWed+CRed and (b) BM+CRed samples.
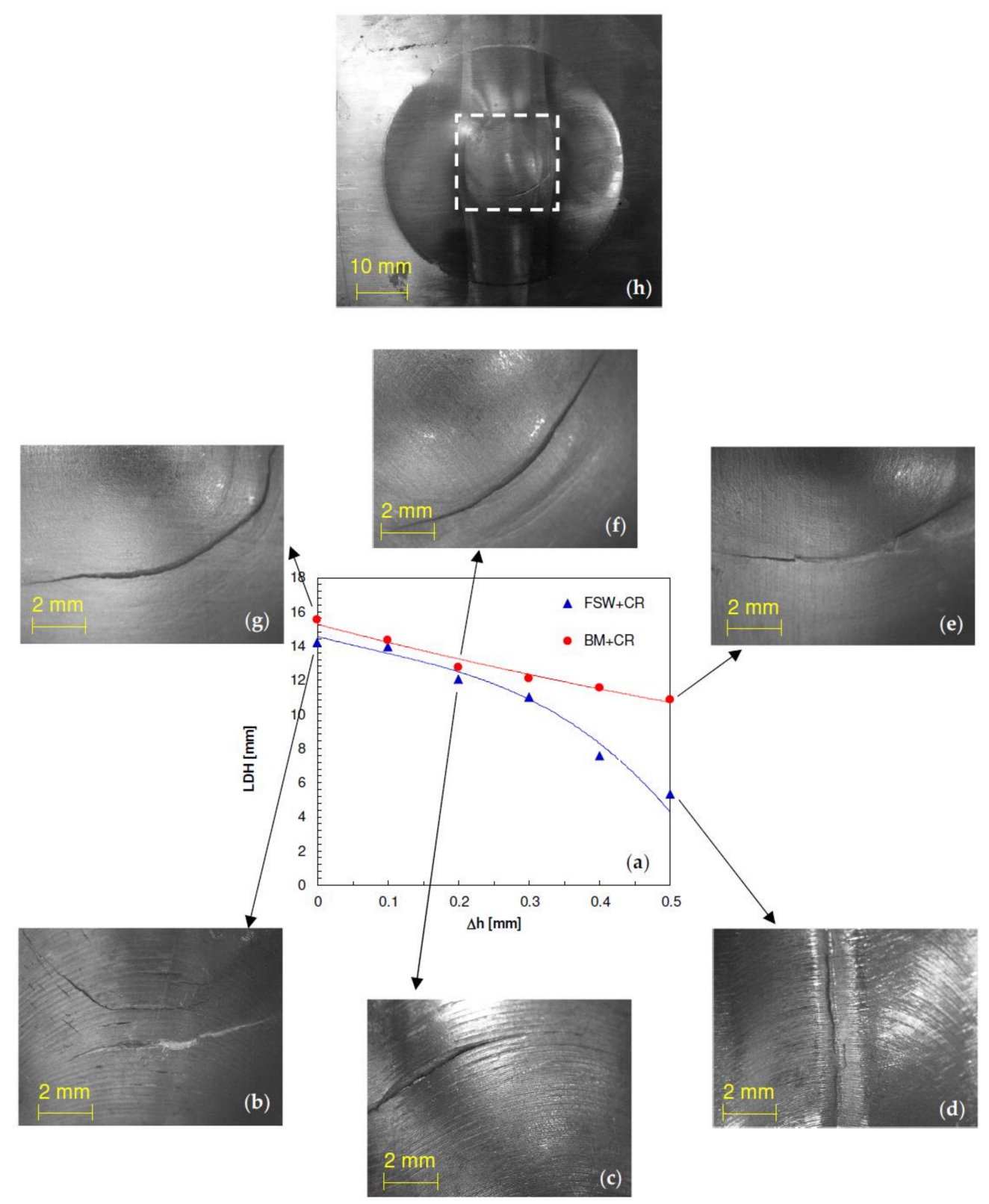

Figure 8. (a) Limiting dome height as a function of height reduction and (b-h) typical fractures on deformed samples in both FSWed+CRed and BM+CRed conditions. 
In both FSWed and in the FSWed+CRed sample with $\Delta h=0.2 \mathrm{~mm}$, ductile fracture occurs in the welded zone (Figure 8b,c), as also shown by Liu et al. in [25]. Crack start developing from the bottom surface, propagate in the direction of the maximum equivalent plastic strain, through the thickness and follows a circumferential path. The resulting fracture surface exhibits a dimpled structure with microvoids. As far as the FSWed+CRed sample with $\Delta h=0.5 \mathrm{~mm}$ is concerned (Figure 8d), localised thinning is observed in the weld seam resulting in elongation along the welding line. The $\mathrm{BM}+\mathrm{CRed}$ condition, irrespective of height reduction, exhibits ductile fracture with a crack following a circumferential path (Figure 8e-g).

\section{Discussion}

The mechanical behaviour obtained by analysing the results of uniaxial tensile tests carried out on FSWed+CRed AA5754 alloy is affected to a greater extent by the strain hardening caused by cold rolling. To this end, Figure 9a shows the strain hardening exponent $(n)$ in the FSWed+CRed condition as a function of $\Delta h$. The decrease in $n$ value with increasing $\Delta h$ leads to the reduction of strain at the onset of necking and, due to the very low post-necking deformation, of the ultimate elongation with increasing $\Delta h$ shown in Figure 3c. However, since the strain hardening exponent in the FSWed+CRed condition is higher than that of the $\mathrm{BM}+\mathrm{CRed}$, with a discrepancy that is almost independent of height reduction, it is expected that $U E_{F S W e d+C R e d}$ would be higher than $U E_{B M+C R e d}$. The reverse behaviour observed in Figure 3c, with the ductility of the FSWed+CRed tensile samples being lower than those of the BM+CRed samples, can be attributed, besides the higher post-necking deformation in the $\mathrm{BM}+\mathrm{CRed}$ condition, to the cracks occurring in welded and cold rolled samples (Figure 4c,d). In fact, by reducing the structural integrity of the material, these factors lead to a decrease in the load carrying capacity of blank.

Figure $9 \mathrm{~b}$ shows the relationship between the ultimate elongation and strain hardening exponent for both FSWed+CRed and BM+CRed conditions investigated. A non-linear direct correlation occurs with an increase in the $U E$ value with $n$, confirming that the ductility is strongly dependent on the strain hardening exponent. Furthermore, it is seen that the $U E$ value grows with $n$ with an almost linear trend as $\Delta h \neq 0$ and exhibits a marked increase as $\Delta h=0$. Finally, the discrepancy between $U E_{B M+C R e d}$ and $U E_{F S W e d+C R e d}$ is low for low $n$ values, i.e., for high $\Delta h$ values, and tends to increase with strain hardening exponent reaching the highest value as the FWSed and BM conditions are compared.

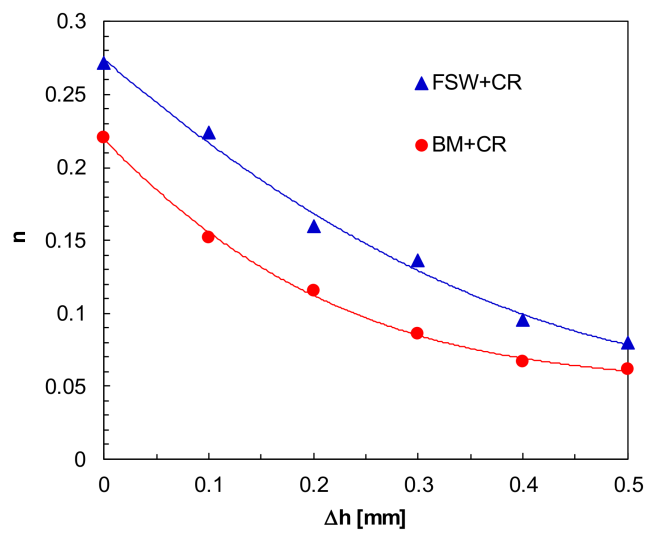

(a)

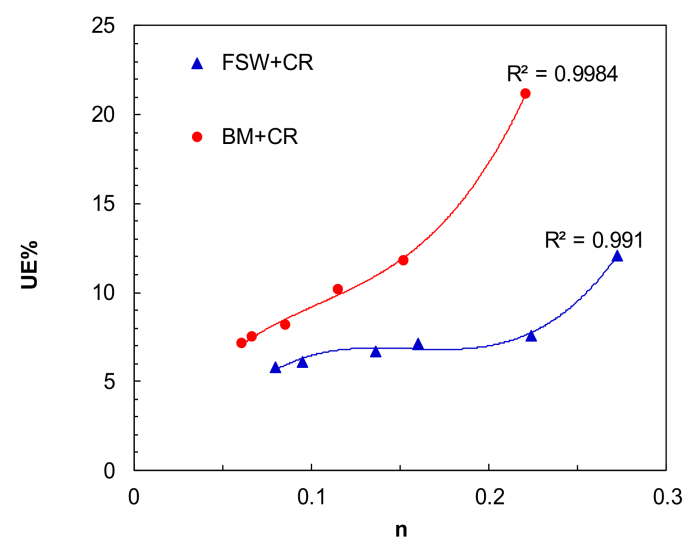

(b)

Figure 9. (a) Strain hardening exponent vs. height reduction and (b) correlation between ultimate elongation and strain hardening exponent in both FSWed+CRed and BM+CRed conditions.

The different mechanical behavior, in terms of strength and strain hardening response, can be rationalised by taking into account the different microstructural phenomena occurring during 
deformation of the tensile samples in both FSWed+CRed and BM+CRed conditions. A simple estimate of the stress at the early beginning of plastic straining can be obtained by the equation:

$$
\sigma=\sigma_{i}+\sigma_{g}+\sigma_{s o l}+\sigma_{\rho}=\sigma_{i}+\sigma_{s o l}+\frac{K}{\sqrt{d}}+\alpha \cdot m \cdot G \cdot b \cdot \sqrt{\rho}
$$

where $\sigma_{i}$ is the strength of the annealed crystal, $\sigma_{\text {sol }}$ is the solid solution strengthening term (mainly due to $\mathrm{Mg}$ ), $\sigma_{\mathrm{g}}$ is the strengthening due to grain refinement, $K$ is a constant, $d$ is the grain size, $\alpha$ is a constant $(=0.3), m$ is the Taylor factor $(=3.06), G$ is the shear modulus, $b$ is the Burgers vector $\left(=2.54 \times 10^{-10} \mathrm{~m}\right)$, and $\rho$ is the dislocation density [26]. At yielding, for undeformed alloys containing $2.5-3 \% \mathrm{Mg}$, the true yield stress $\left(\sigma_{y}\right)$ can be calculated as:

$$
\sigma_{y}=\sigma_{i}+\sigma_{g}+\sigma_{s o l}+\sigma_{\rho}=\left(\sigma_{i}+\sigma_{s o l}+\alpha \cdot m \cdot G \cdot b \cdot \sqrt{\rho}\right)+\frac{K}{\sqrt{d}} \cong \sigma_{i}+\sigma_{\text {sol }}+\frac{K}{\sqrt{d}}=30 \mathrm{MPa}+\frac{6}{\sqrt{d}}
$$

where $d$ is in $\mathrm{mm}[26,27]$. A rough quantification of the strengthening contributions of the different mechanisms can be simply obtained by considering that, in the nugget, dynamic recrystallization (DRX) results in grain refinement (Figure 10). The initial grain size, roughly estimated, for AA5754, in $50 \mu \mathrm{m}$ [23], can be reduced down to $10 \mu \mathrm{m}$. Thus, DRX in the nugget should produce an increase in strength of the FSW material, due to grain refinement, close to $35 \mathrm{MPa}$. On the other hand, in the H114 temper state, i.e., in lightly cold worked condition, the BM contains a relatively high dislocation density. DRX during FSW causes a dramatic reduction in dislocation density, which can decrease down to the typical values for the annealed state $\left(10^{11}-10^{12} \mathrm{~m}^{-2}\right)$. Taking $\rho=1 \times 10^{12} \mathrm{~m}^{-2}$ for the FSWed condition and $\rho=2.5 \times 10^{14} \mathrm{~m}^{-2}$ for AA5754-H114 one [28], dislocation hardening contribution can be quantified in 6 and $100 \mathrm{MPa}$, respectively. With $\left(\sigma_{i}+\sigma_{\text {sol }}\right)=30 \mathrm{MPa}$ (the strength of the lattice, which includes any solid solution hardening term), this calculation gives a yield strength of 96 and $156 \mathrm{MPa}$, respectively, for the FSWed and H114 states. These estimates of the $\sigma_{y}$ are in excellent agreement with the experimental values, 101 and $164 \mathrm{MPa}$ for FSW and initial condition, respectively, and clearly demonstrate that the dislocation hardening term is predominant in the strain hardened state, while grain refining is more important in the FSW state.

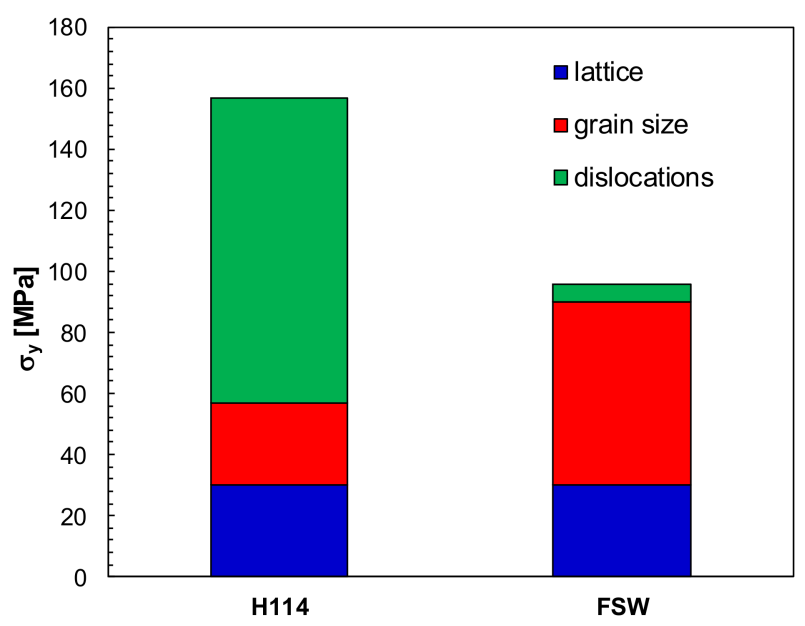

Figure 10. Quantification of the strengthening contributions given by the different mechanisms.

By considering the hardening capacity, defined as $[29,30]$ as:

$$
H_{c}=\frac{U T S-Y S}{Y S} .
$$


where it can be seen a decrease in the ability of the materials to strain harden with increasing $\Delta h$ (Figure 11). Consistently with the behaviour shown by $n$, the $H_{C}$ values in the FSWed+CRed condition are higher than those in the $\mathrm{BM}+\mathrm{CRed}$ one. The results shown in Figure 9 are related to the strain hardening behaviour of AA5754-H114 alloy which is affected mainly by the dislocation density and grain size. For the FSWed joints, the grain refinement in the nugget zone caused by the dynamic recrystallization, observed by the authors in [23], is beneficial to the strain hardening; the nugget zone shows a lower dislocation density than that in the BM [29,31]. Thus, additional straining of the soft structure, in terms of dislocation content, causes a rapid increase in $\rho$ and a high value of $H_{C}$. The alloy in H114 state, by contrast, contains a non-negligible dislocation content already before straining; the cold rolling process introduces additional dislocations leading to the increase in the tensile strength, is somewhat lower than in the case of the initially softer FSWed material.

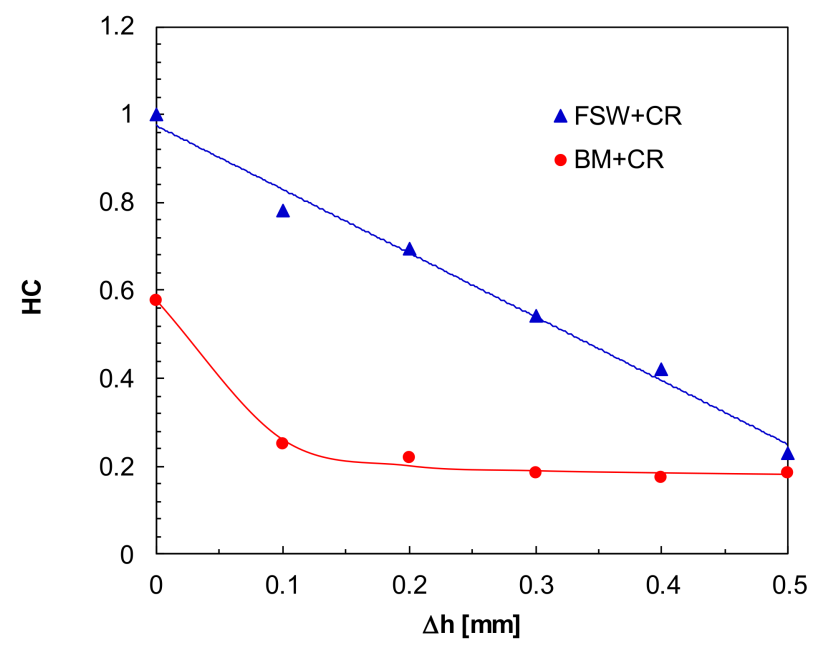

Figure 11. Hardening capacity vs. height reduction in both FSWed+CRed and BM+CRed conditions.

A further contribution to the decrease of both strength and ductility of the FSWed workpieces can be attributed to the discontinuity located at the bottom side of the weld, as shown in Figure 12, due to the small clearance between the bottom side of the pin and backing plate [21,22]. Such a defect is about $180 \mu \mathrm{m}$ in depth and $40 \mu \mathrm{m}$ in width. To this end, Figure 13a shows the SEM image of a fractured surface of a tensile sample obtained on the FSWed+CRed workpiece with $\Delta h=0.1 \mathrm{~mm}$. The discontinuity is clearly visible near the bottom surface since, owing to the small height reduction, cold rolling does not allow to reduce the depth of the FSW defect. On the contrary, with $\Delta h=0.5 \mathrm{~mm}$, the depth of the discontinuity is almost negligible owing to marked thinning imparted by cold rolling (Figure 13b).

As far as formability is concerned, the decrease in the limiting dome height with increasing $\Delta h$ shown in Figure 8a is related to both the reduction in the strain hardening exponent and the sheet thickness with rising the number of rolling passes [32]. The $L D H$ vs. $\Delta h$ behaviour in the FSWed+CRed condition differs from that observed in the BM+CRed due to the non-uniform mechanical properties exhibited by the FSWed+CRed samples in the weld seam along the direction of the welding line and its perpendicular $[17,33]$. Consequently, the strain level taking place during the hemispherical punch test of the FSWed+CRed samples along the welding line is lower than the strain lever in the direction perpendicular to the welding line. Such an effect becomes more pronounced as height reduction imposed by $\mathrm{CR}$ increases due to strain hardening and leads to an unbalanced stress state with necking insurgence along the welding line (Figure $8 \mathrm{~d}$ ). 

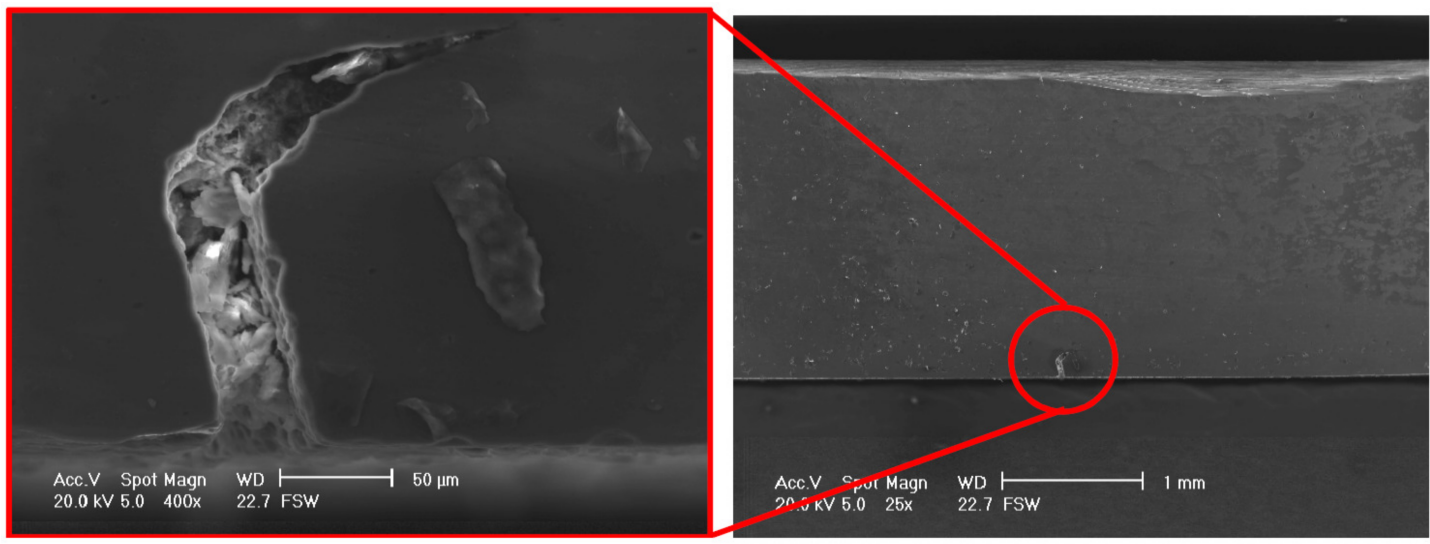

Figure 12. Scanning electron microscope (SEM) images showing the discontinuity located in the bottom side of the weld before cold rolling.

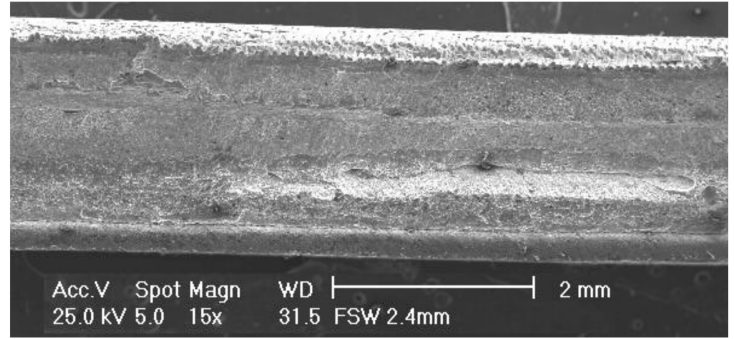

(a)

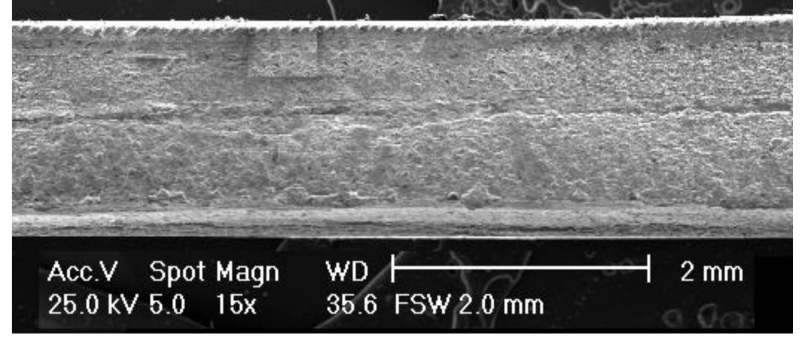

(b)

Figure 13. Scanning electron microscope fractography of the FSWed+CRed samples deformed in the cold rolling direction: (a) $\Delta h=0.1 \mathrm{~mm}$; (b) $\Delta h=0.5 \mathrm{~mm}$.

\section{Conclusions}

The influence of cold rolling, performed after friction stir welding, on the mechanical properties and formability of joints in AA5754-H114 aluminium alloy was widely studied. To this end, friction stir welding on $2.5 \mathrm{~mm}$ thick sheets, with constant values of rotation and welding speeds, was carried out. The welded workpieces were then subjected to cold rolling, with the rolling direction perpendicular to the welding line, with height reductions ranging between 0.1 and $0.5 \mathrm{~mm}$. In addition, the base material was cold rolled to obtain the same thicknesses of FSWed+CRed workpieces. Samples obtained in both conditions were tested by tensile and hemispherical punch tests, and analysed by scanning electron microscopy.

The main results obtained can be summarised as follows:

1. The yield strength and ultimate tensile strength in the FSWed+CRed condition are higher than those in the FSWed. Such discrepancy increases with the height reduction imposed by cold rolling. On the contrary, the ultimate elongation in the FSWed+CRed condition is lower than that in the FSWed, with a difference that grows with height reduction,

2. The yield strength, ultimate tensile strength, and ultimate elongation in the FSWed+CRed condition are lower than those in BM+CRed one.

3. The mechanical behaviour is strongly affected to by the strain hardening caused by cold rolling. In particular, the strain hardening exponent and hardening capacity decrease with increasing height reduction with the FSWed+CRed condition characterised.

4. The SEM images of FSWed+CRed samples show a ductile behaviour with the microvoid coalescence even though cracks propagating along the direction of welding motion appears. The BM+CRed samples exhibit a ductile fracture surface morphology. 
5. The limiting dome height decreases with increasing height reduction. In the FSWed+CRed condition the $L D H$ values are slightly lower than those in the BM+CRed one until a height reduction of $0.2 \mathrm{~mm}$; as $\Delta h$ further increases, such discrepancy strongly grows.

Acknowledgments: Massimiliano Pieralisi, Luciano Greco, and Daniele Ciccarelli are acknowledged for their contribution in the experimental work.

Author Contributions: Mohamad El Mehtedi, Archimede Forcellese and Michela Simoncini conceived and designed the experiments; Mohamad El Mehtedi and Michela Simoncini performed the experiments; Michela Simoncini and Giuseppe Casalino analyzed the data; Archimede Forcellese wrote the manuscript, Archimede Forcellese and Michela Simoncini edited the manuscript.

Conflicts of Interest: The authors declare no conflict of interest.

\section{References}

1. Mishra, R.S.; Ma, Z.Y. Friction stir welding and processing. Mater. Sci. Eng. R 2005, 50, 1-78. [CrossRef]

2. Wonoh, L.; Kyung-Hwan, C.; Daeyong, K.; Junehyung, K.; Chongmin, K.; Kazutaka, O.; Wagoner, R.H.; Kwansoo, C. Experimental and numerical study on formability of friction stir welded TWB sheets based on hemispherical dome stretch tests. Int. J. Plast. 2009, 25, 1626-1654. [CrossRef]

3. Padhy, G.K.; Wu, C.S.; Gao, S. Friction stir based welding and processing technologies-Processes, parameters, microstructures and applications: A review. J. Mater. Sci. Technol. 2018, 34, 1-38. [CrossRef]

4. Mahdi Moradi, M.; Jamshidi Aval, H.; Jamaati, R.; Amirkhanlou, S.; Ji, S. Microstructure and texture evolution of friction stir welded dissimilar aluminum alloys: AA2024 and AA6061. J. Manuf. Process. 2018, 32, 1-10. [CrossRef]

5. Contuzzi, N.; Campanelli, S.L.; Casalino, G.; Ludovico, A.D. On the role of the thermal contact conductance during the friction stir welding of an AA5754-H111 butt joint. Appl. Therm. Eng. 2016, 104, 263-273. [CrossRef]

6. Forcellese, A.; Simoncini, M.; Casalino, G. Influence of process parameters on the vertical forces generated during friction stir welding of AA6082-T6 and on the mechanical properties of the joints. Metals 2017, 7, 350. [CrossRef]

7. Bruni, C.; Forcellese, A.; Gabrielli, F.; Simoncini, M. Post-welding formability of AZ31 magnesium alloy. Mater. Des. 2011, 32, 2988-2991. [CrossRef]

8. Forcellese, A.; Simoncini, M. Plastic flow behaviour and formability of FSWed joints in AZ31 thin sheets obtained using the "pinless" tool configuration. Mater. Des. 2012, 36, 123-129. [CrossRef]

9. Simoncini, M.; Forcellese, A. Effect of the welding parameters and tool configuration on micro- and macro-mechanical properties of similar and dissimilar FSWed joints in AA5754 and AZ31 thin sheets. Mater. Des. 2012, 41, 50-60. [CrossRef]

10. Kleiner, M.; Geiger, M.; Klaus, A. Manufacturing of lightweight components by metal forming. CIRP Ann. 2003, 52, 521-542. [CrossRef]

11. Fratini, L.; Buffa, G.; Shivpuri, R. Improving friction stir welding of blanks of different thicknesses. Mater. Sci. Eng. A 2007, 459, 209-215. [CrossRef]

12. Simoncini, M.; Ciccarelli, D.; Forcellese, A.; Pieralisi, M. Micro- and macro- mechanical properties of pinless friction stir welded joints in AA5754 aluminium thin sheets. Procedia CIRP 2014, 18, 9-14. [CrossRef]

13. Lertora, E.; Gambaro, C.; Mandolfino, C.; Pedemonte, M. Friction stir welding between extrusions and laminates. Weld. Int. 2015, 29, 117-123. [CrossRef]

14. Fratini, L.; Buffa, G.; Shivpuri, R. Finite element studies on friction stir welding processes of tailored blanks. Comput. Struct. 2008, 86, 181-189. [CrossRef]

15. Guerra, M.; Schmidt, C.; McClure, J.C.; Murr, L.E.; Nunes, A.C. Flow patterns during friction stir welding. Mater. Charact. 2003, 49, 95-101. [CrossRef]

16. Casalino, G.; Campanelli, S.; Mortello, M. Influence of shoulder geometry and coating of the tool on the friction stir welding of aluminium alloy plates. Procedia Eng. 2014, 69, 1541-1548. [CrossRef]

17. Hirata, T.; Oguri, T.; Hagino, H.; Tanaka, T.; Wook Chung, S.; Takigawa, Y.; Higashi, K. Influence of friction stir welding parameters on grain size and formability in 5083 aluminum alloy. Mater. Sci. Eng. A 2007, 456, 344-349. [CrossRef] 
18. Cabibbo, M.; Forcellese, A.; Simoncini, M. New approaches to the friction stir welding of aluminum alloys. In Joining Technologies; Mahadzir, Ishak, Ed.; InTech: Rijeka, Croatia, 2016; pp. 7-26.

19. Lertora, E.; Mandolfino, C.; Gambaro, C. Effect of welding parameters on AA8090 Al-Li alloy FSW T-joints. Key Eng. Mater. 2013, 554-557, 985-995. [CrossRef]

20. Rodrigues, D.M.; Loureiro, A.; Leitao, C.; Leal, R.M.; Chaparro, B.M.; Vilaça, P. Influence of friction stir welding parameters on the microstructural and mechanical properties of AA 6016-T4 thin welds. Mater. Des. 2009, 30, 1913-1921. [CrossRef]

21. Forcellese, A.; Fratini, L.; Gabrielli, F.; Simoncini, M. Formability of friction stir welded AZ31 magnesium alloy sheets. Mater. Sci. Forum 2010, 638-642, 1249-1254. [CrossRef]

22. Simoncini, M.; Cabibbo, M.; Forcellese, A. Development of double-side friction stir welding to improve post-welding formability of joints in AA6082 aluminium alloy. Proc. IMechE B: J. Eng. Manuf. 2016, 230, 807-817. [CrossRef]

23. Gabrielli, F.; Forcellese, A.; El Mehtedi, M.; Simoncini, M. Mechanical properties and formability of cold rolled friction stir welded sheets in AA5754 for automotive applications. Procedia Eng. 2017, 183, 245-250. [CrossRef]

24. Ciarapica, F.; D'Orazio, A.; Forcellese, A.; Simoncini, M. Sustainability analysis of friction stir welding of AA5754 sheets. Procedia CIRP 2017, 62, 529-534. [CrossRef]

25. Liu, H.J.; Fujii, H.; Maeda, M.; Nogi, K. Tensile properties and fracture locations of friction-stir-welded joints of 2017-T351 aluminum alloy. J. Mater. Process. Technol. 2003, 142, 692-696. [CrossRef]

26. Spigarelli, S.; Paoletti, C. A unified physical model for creep and hot working of Al-Mg solid solution alloys. Metals 2018, 8, 9. [CrossRef]

27. Armstrong, R.W.; Douthwaite, R.M. Hall-Petch basis for assessing alloy strengthening. In Grain Size and Mechanical Properties_Fundamentals and Applications; Otooni, M.A., Armstrong, R.W., Grant, N.J., Ishizaki, K., Eds.; Materials Research Society: Pittsburgh, PA, USA, 1995; pp. 41-47.

28. Wang, S.C.; Zhu, Z.; Starink, M.J. Estimation of dislocation densities in cold rolled Al-Mg-Cu-Mn alloys by combination of yield strength data, EBSD and strength models. J. Microsc. 2005, 217, 174-178. [CrossRef] [PubMed]

29. Afrin, N.; Chen, D.L.; Cao, X.; Jahazi, M. Strain hardening behavior of a friction stir welded magnesium alloy. Scr. Mater. 2007, 57, 1004-1007. [CrossRef]

30. Ni, D.R.; Chen, D.L.; Wang, D.; Xiao, B.L.; Ma, Z.Y. Tensile properties and strain-hardening behavior of friction stir welded SiCp/AA2009 composite joints. Mater. Sci. Eng. A 2014, 608, 1-10. [CrossRef]

31. Nandan, R.; DebRoy, T.; Bhadeshia, H.K.D.H. Recent advances in friction-stir welding-Process, weldment structure and properties. Progress Mater. Sci. 2008, 53, 980-1023. [CrossRef]

32. Budai, D.; Tisza, M.; Zoltán Kovács, P. Investigation of the formability of EN AW 5754 aluminium alloy sheets with different thickness. In International Multidisciplinary Scientific Conference; University of Miskolc: Miskolc, Hungary, 2016; ISBN 978-963-358-113-1.

33. Simoncini, M.; Panaccio, L.; Forcellese, A. Bending and stamping processes of FSWed thin sheets in AA1050 alloy. Key Eng. Mater. 2014, 622-623, 459-466. [CrossRef]

(C) 2018 by the authors. Licensee MDPI, Basel, Switzerland. This article is an open access article distributed under the terms and conditions of the Creative Commons Attribution (CC BY) license (http://creativecommons.org/licenses/by/4.0/). 